\title{
Effects of ethanol, acetaldehyde and cholesteryl esters on pancreatic lysosomes
}

\author{
J S Wilson, M V Apte, M C Thomas, P S Haber, R C Pirola
}

\begin{abstract}
Recent studies indicate that altered lysosomal function may be involved in the early stages of pancreatic injury. Chronic consumption of ethanol increases rat pancreatic lysosomal fragility. The aim of this study is to determine whether the lysosomal fragility observed after chronic ethanol consumption is mediated by ethanol per se, its oxidative metabolite acetaldehyde or cholesteryl esters (substances which accumulate in the pancreas after ethanol consumption). Pancreatic lysosomes from chow fed rats were incubated for $\mathbf{3 0}$ minutes at $37^{\circ} \mathrm{C}$ with ethanol, acetaldehyde or phosphatidylcholine vesicles containing cholesteryl oleate. Lysosomal stability was then assessed by determination of: (a) Latency - that is, the per cent increase in lysosomal enzyme activity after addition of Triton X-100 and (b) Supernatant activity - that is, the proportion of lysosomal enzyme remaining in the supernatant after resedimentation of lysosomes. Acid phosphatase, $\mathbf{N}$-acetyl glucosaminidase, $\beta$-glucuronidase and cathepsin $B$ were assayed as lysosomal marker enzymes. Lysosomes incubated with homogenising medium alone or equivalent volumes of phosphatidylcholine vesicles without cholesteryl oleate were used as controls. Cholesteryl oleate at concentrations of 15 and $20 \mathrm{mM}$ increased pancreatic lysosomal fragility as shown by decreased latency and increased supernatant enzyme. In contrast, ethanol $(150 \mathrm{mM})$ and acetaldehyde ( $5 \mathrm{mM}$ ) had no effect on lysosomal stability in vitro. These results suggest that increased pancreatic lysosomal fragility observed with ethanol may be mediated by cholesteryl ester accumulation rather than by ethanol or acetaldehyde.
\end{abstract}

(Gut 1992; 33: 1099-1104)

Abuse of ethanol is a known association of pancreatitis.' The mechanisms whereby ethanol exerts its pancreatotoxic effects, however, are unknown. Over the past decade, digestive enzyme activation by lysosomal hydrolases (particularly cathepsin B) ${ }^{2}$ has been implicated as the initial event in three forms of experimental pancreatitis. ${ }^{3-5}$ Furthermore, recent studies from this laboratory have shown that experimental ethanol administration increases the fragility of rat pancreatic lysosomes. ${ }^{6}$

The increase in pancreatic lysosomal fragility could result from a direct effect of ethanol on lysosomal membranes. In vivo and in vitro animal studies have shown that ethanol alters the morphology and/or function of membranes of hepatocytes, ${ }^{7-9}$ erythrocytes, ${ }^{10}$ intestinal microvilli, ${ }^{11}$ and brain microsomes. ${ }^{12}$
Alternatively, the increased lysosomal fragility may be mediated by acetaldehyde. This highly reactive metabolite of ethanol has been shown to form adducts with liver plasma membranes which result in activation of the complement sequence. ${ }^{131+}$ In addition, Tillotson et al ${ }^{11}$ have shown that acetaldehyde increases membrane permeability and fluidity as well as inhibiting $\mathrm{Na}^{+}$-stimulated glucose transport in rat intestinal microvillus membranes.

An additional possibility is that cholesteryl esters alter lysosomal stability. Fat droplet accumulation in acinar cells has been observed as the earliest morphologic alteration in the pancreas of alcoholics. ${ }^{1516}$ This phenomenon has been reproduced in a rat model of ethanol feeding ${ }^{17}$ and subsequent lipid analyses indicated that accumulated cholesteryl esters were responsible for the morphologic changes observed. ${ }^{178}$ These compounds (Fig 1) are known to disrupt biologic membranes in vitro ${ }^{19} 20$ and therefore have the potential to mediate the increased pancreatic lysosomal fragility observed in ethanol fed rats.

The aim of this study was to determine whether ethanol induced fragility of pancreatic lysosomes is mediated by ethanol, its oxidative metabolite acetaldehyde or cholesteryl esters. To study this question, the stability of pancreatic lysosomes was assessed after exposure in vitro to ethanol, acetaldehyde, and the cholesteryl ester, cholesteryl oleate.

\section{Methods}

\section{EXPERIMENTAL ANIMALS}

Chow fed male Sprague-Dawley rats weighing 300-350 g were used in all experiments. Each animal was killed in the fed state by decapitation. A portion of the tail of the pancreas was then quickly excised, trimmed of adipose and connective tissue and used immediately.

ISOLATION OF PANCREATIC LYSOSOMES

Pancreatic lysosomes were isolated by a modification of the method of Ignarro et $a l^{21}$ as previously described. ${ }^{6}$ Briefly, approximately 100 mg pancreatic tissue from each animal was homogenized in a medium containing $0.25 \mathrm{M}$ sucrose, $1 \mathrm{mM}$ ethylenediaminetetraacetic acid (EDTA) and $25 \mathrm{mg} \%$ soybean trypsin inhibitor in a Dounce homogeniser (using five up and down strokes of the ' $B$ ' pestle). The resulting crude homogenate was then centrifuged at $600 \mathrm{~g}$ for 10 minutes to remove unbroken cells and nuclear debris. The resulting pellet was resuspended, rehomogenised and centrifuged as above. Supernatants were combined and centri- 


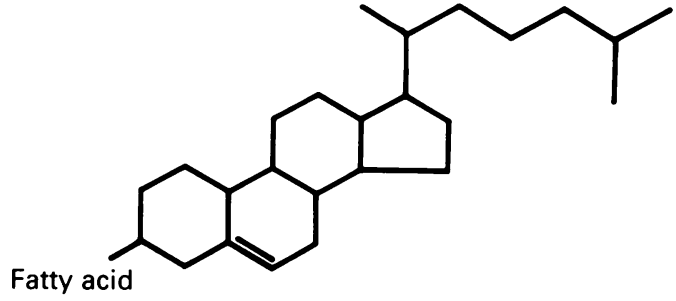

Figure 1: Cholesteryl esters consist of a cholesterol molecule esterified at the 3 position with a fatty acid moiety. They can be incorporated into biologic membranes where they may exert a disordering effect (see text).

fuged at $16500 \mathrm{~g}$ for 25 minutes to obtain a lysosome enriched pellet. Electron microscopic analysis of the pellet revealed the presence of zymogen granules as well as lysosomes. The pellet was then gently resuspended in $10 \mathrm{ml}$ homogenising medium and used for incubation with ethanol, acetaldehyde, or cholesteryl oleate. A lysosome enriched fraction rather than a pure lysosomal preparation was used because preliminary experiments indicated a loss of lysosomal stability with prolonged preparative procedures.

\section{PREPARATION OF PHOSOPHOLIPID VESICLES}

Experiments examining the effect of cholesteryl esters on the stability of isolated pancreatic lysosomes were carried out using cholesteryl oleate incorporated into phosphatidylcholine vesicles. This was done in order to avoid phase separations during the incubation process. Vesicles were prepared by the method of Chobanian, Tall, and Brecher. ${ }^{22}$ Egg yolk lecithin (phosphatidylcholine) and cholesteryl oleate were dissolved in chloroform:methanol $(2: 1)$ and mixed together in a molar ratio of $25: 1$ as Forrest and Cushley ${ }^{19}$ have reported that a maximum of $5 \mathrm{~mol} \%$ of cholesteryl ester can be incorporated into phosphatidylcholine vesicles. The lipid mixture was evaporated under $\mathrm{N}_{2}$, lyophilised overnight and resuspended in 250 $\mu \mathrm{M} \mathrm{NaCl}-25 \mu \mathrm{M}$ Tris buffer ( $\mathrm{pH} \mathrm{7 \cdot 4).}$ Unilamellar vesicles were prepared by sonication as described by Barrow and Lent $\mathrm{z}^{23}$ in a nitrogen atmosphere using a Heat Systems Cup Horn Sonicator (Heat Systems Ultrasonics Inc, NY, USA) at an output setting of 4 , for 55 minutes at $25-35^{\circ} \mathrm{C}$. Care was taken to place the vial in the centre of the 'cavitation umbrella' of the Cup Horn. After sonication, the sample was centrifuged at $150000 \mathrm{~g}$ for one hour to yield a faintly opalescent supernatant consisting of a homogeneous population of cholesteryl oleate vesicles.

\section{CHARACTERISATION OF VESICLES}

(a) Sizing

Lipid vesicles were sized by photon correlation spectroscopy as described by Barenholz et $a^{24}$ using a Malvern Autosizer II C. The mean diameter of the vesicles was 605 (15) $\AA$. The polydispersity index of the preparation was $0 \cdot 33$.
$\mathrm{NaCl}$-Tris buffer and examined by electron microscopy using: (i) Negative staining with sodium phosphotungstate as described by Tall et $a l,{ }^{25}$ and (ii) Platinum coating of vesicles on a carbon free hydrophilic grid as described by Huang. ${ }^{26}$

\section{(c) Cholesteryl oleate concentration}

Recovery of added labelled cholesteryl oleate (cholesteryl $\left[1-{ }^{14} \mathrm{C}\right]$ oleate, specific activity 52 $\mathrm{mCi} / \mathrm{mmol}$ ), was used to estimate the concentration of cholesteryl oleate in the liposome preparation.

\section{(d) Free fatty acid concentration}

The concentration of free fatty acids in the vesicle preparation was determined by thin layer chromatography followed by gas chromatography mass spectroscopy. The vesicle preparation was freeze dried overnight and resuspended in chloroform:methanol $(2: 1)$ at a concentration of $20 \mathrm{mg} \mathrm{lipid} / \mathrm{ml}$ solvent. This preparation was then applied to standard silica gel thin layer chromatography plates together with phosphatidylcholine, cholesteryl oleate, and oleic acid standards. Plates were developed in chloroform: methanol:water (65:25:4 v/v/v) and the bands visualised by iodine staining. The free fatty acid band was identified and scraped off the plate. Free fatty acids were then eluted three times with methanol acidified to $\mathrm{pH} 3$ by the addition of a few drops of acetic acid. Free fatty acids were methylated by the method of Howard-Black ${ }^{27}$ using excess etherial diazomethane and then identified and quantified using gas chromatography mass spectroscopy. The vesicle preparation was thus found to contain $13.9 \mu \mathrm{g}$ palmitic acid and $11.5 \mu \mathrm{g}$ oleic acid $/ \mathrm{ml}$. The maximum concentration of free fatty acid in the incubation mixture was calculated to be $50 \mu \mathrm{M}$.

INCUBATION OF LYSOSOMES WITH ETHANOL AND ACETALDEHYDE

Isolated pancreatic lysosomes were incubated with ethanol or acetaldehyde in tightly sealed tubes for 30 minutes at $37^{\circ} \mathrm{C}$. The concentrations of ethanol and acetaldehyde in the incubation medium were $150 \mathrm{mM}$ and $5 \mathrm{mM}$ respectively. Lysosomes incubated with the homogenising medium alone were used as controls.

\section{INCUBATION OF LYSOSOMES WITH CHOLESTERYL}

\section{OLEATE}

Isolated pancreatic lysosomes were incubated with phosphatidylcholine vesicles containing cholesteryl oleate for 30 minutes at $37^{\circ} \mathrm{C}$. The concentration of cholesteryl oleate in the incubation medium ranged from 10 to $20 \mathrm{mM}$. Control incubations used equivalent amounts of phosphatidylcholine vesicles without cholesteryl oleate.

INCUBATION OF LYSOSOMES WITH FREE FATTY ACID

In some experiments, lysosomes were incubated 
with oleic acid which had been emulsified in 250 $\mu \mathrm{M} \mathrm{NaCl}-25 \mu \mathrm{M}$ Tris buffer $(\mathrm{pH} \mathrm{7.4)}$ by sonication under nitrogen as described by Nagai et $a l^{28}$ using a Heat Systems Cup Horn Sonicator at an output setting of four for 10 minutes at $25^{\circ} \mathrm{C}$. Lysosomes were then incubated at $37^{\circ} \mathrm{C}$ for 30 minutes with $50 \mu \mathrm{M}$ oleic acid; this concentration of oleic acid corresponded to the maximum amount of free fatty acid present in the liposome preparation. Lysosomes incubated in the presence of buffer alone were used as controls.

\section{ASSESSMENT OF LYSOSOMAL STABILITY}

Lysosomal stability was assessed in two ways: (i) Determination of latency - that is, the percentage increase in lysosomal enzyme activity of the incubated sample after the addition of Triton X-100 $(0 \cdot 1 \%$ final concentration $)$ Latency was calculated as follows:

(enzyme activity after Triton)-(enzyme activity before Triton) enzyme activity before Triton

Increased lysosomal fragility is indicated by a decrease in latency. (ii) Determination of the proportion of total enzyme released into the supernatant after resedimentation of lysosomes from the incubated samples by centrifugation at $16500 \mathrm{~g}$ for 25 minutes. Increased lysosomal fragility is indicated by an increase in supernatant enzyme. There was no increase in lysosomal enzyme activity after the addition of Triton X-100 to the supernatant suggesting that supernatant enzymes were in the free form - that is, not membrane bound.

The presence of zymogen granules in the lysosome enriched fraction did not interfere with the assessment of lysosomal stability as this was measured using enzyme markers specific for lysosomes (vide infra).

\section{LYSOSOMAL MARKER ENZYMES}

The lysosomal enzymes $\mathrm{N}$-acetyl glucosaminidase, acid phosphatase and $\beta$-glucuronidase were assayed fluorimetrically using 4-methylumbelliferone substrates. ${ }^{29}$ Activity was determined by measuring the amount of 4 methylumbelliferone released after incubation with the enzyme source. Cathepsin B was assayed fluorimetrically by the method of McDonald and Ellis, ${ }^{30}$ as modified by Saluja et al, ${ }^{31}$ using CBZ-Arg-Arg- $\beta$-naphthylamide as the substrate. Activity was determined from the

Effect of ethanol ( $150 \mathrm{mM})$ and acetaldehyde $(5 \mathrm{mM})$ on pancreatic lysosomal latency and on the proportion of lysosomal enzyme released into the supernatant as indices of lysosomal stability (Methods). Results are expressed as per cent of control values and are presented as means $(S E M)$ (four experiments)

\begin{tabular}{|c|c|c|c|c|}
\hline \multirow[b]{2}{*}{ Lysosomal enzyme } & \multicolumn{2}{|c|}{ Ethanol $(150 \mathrm{mM})$} & \multicolumn{2}{|c|}{ Acetaldehyde $(5 \mathrm{mM})$} \\
\hline & Latency & $\begin{array}{l}\text { Supernatant } \\
\text { enzyme }\end{array}$ & Latency & $\begin{array}{l}\text { Supernatant } \\
\text { enzyme }\end{array}$ \\
\hline $\begin{array}{l}\text { Cathepsin B } \\
\text { N-acetyl glucosaminidase } \\
\text { Acid phosphatase } \\
\beta \text {-glucuronidase }\end{array}$ & $\begin{array}{l}115 \cdot 1(20 \cdot 4) \\
117 \cdot 4(8 \cdot 0) \\
106 \cdot 5(10 \cdot 6) \\
117 \cdot 5(14 \cdot 6)\end{array}$ & $\begin{array}{c}101 \cdot 5(0 \cdot 8) \\
175 \cdot 5(44 \cdot 9) \\
113 \cdot 5(5 \cdot 2) \\
94 \cdot 7(15 \cdot 6)\end{array}$ & $\begin{array}{l}104 \cdot 9(8 \cdot 9) \\
123 \cdot 8(7 \cdot 2) \\
112 \cdot 7(37 \cdot 8) \\
109 \cdot 2(15 \cdot 6)\end{array}$ & $\begin{array}{c}101.9(0 \cdot 9) \\
75.6(19 \cdot 4) \\
99 \cdot 6(7 \cdot 6) \\
89 \cdot 5(10 \cdot 5)\end{array}$ \\
\hline
\end{tabular}

No significant differences were found between the groups for each of the four marker enzymes studied. rate of change of fluorescence as a result of the release of $\beta$-naphthylamide after incubation with the enzyme source. All lysosomal enzyme assays were linear with respect to time and protein concentration. Triton X-100 $(0 \cdot 1 \%$ final concentration) was added to the reaction mixture in order to determine the total amount of lysosomal enzyme present in each lysosomal fraction studied. Tissue protein concentrations were determined by the method of Lowry et al..$^{32}$

\section{STATISTICAL ANALYSIS}

Data were expressed as means (SEM). Differences between samples incubated with ethanol, acetaldehye or cholesteryl oleate and control samples were analysed by Student's $t$ test for paired comparisons. ${ }^{33}$

\section{MATERIALS}

All chemicals were of analytical reagent grade. Cholesteryl oleate and phosphatidylcholine (99.9\% pure) were purchased from the Sigma Chemical Company, St Louis, MO, USA, and eluted as single bands when chromatographed on thin layer chromatography plates. Methylumbelliferone substrates were also purchased from Sigma Chemical Company, St Louis, MO, USA. CBZ-Arg-Arg- $\beta$-naphthylamide was purchased from BACHEM, California, USA. Ethanol (96\%) was obtained from Ajax Chemicals, Australia and acetaldehyde (99\% pure) was purchased from BDH Ltd, Poole, England. Cholesteryl $\left[1-{ }^{14} \mathrm{C}\right]$ oleate was obtained from Amersham, Bucks, England.

\section{Results}

EFFECT OF ETHANOL AND ACETALDEHYDE ON LYSOSOMAL STABILITY

\section{Lysosomal latency}

The Table indicates the latency results obtained with control, ethanol and acetaldehyde incubated lysosomes. For all four lysosomal marker enzymes studied, there was no significant difference between the latency of lysosomes incubated with ethanol or acetaldehyde when compared with control values.

\section{Proportion of lysosomal enzymes in supernatant}

The Table also indicates the proportion of lysosomal enzymes released into the supernatant after sedimentation of incubated pancreatic lysosomes. Again for all four marker enzymes studied, lysosomes incubated with ethanol or acetaldehyde showed no difference in the proportion of lysosomal enzyme released into the supernatant when compared with control values.

\section{EFFECT OF CHOLESTERYL ESTER ON LYSOSOMAL STABILITY \\ Lysosomal latency}

Figure 2 (a-d) depicts the effect of increasing concentrations of cholesteryl oleate on lysosomal 

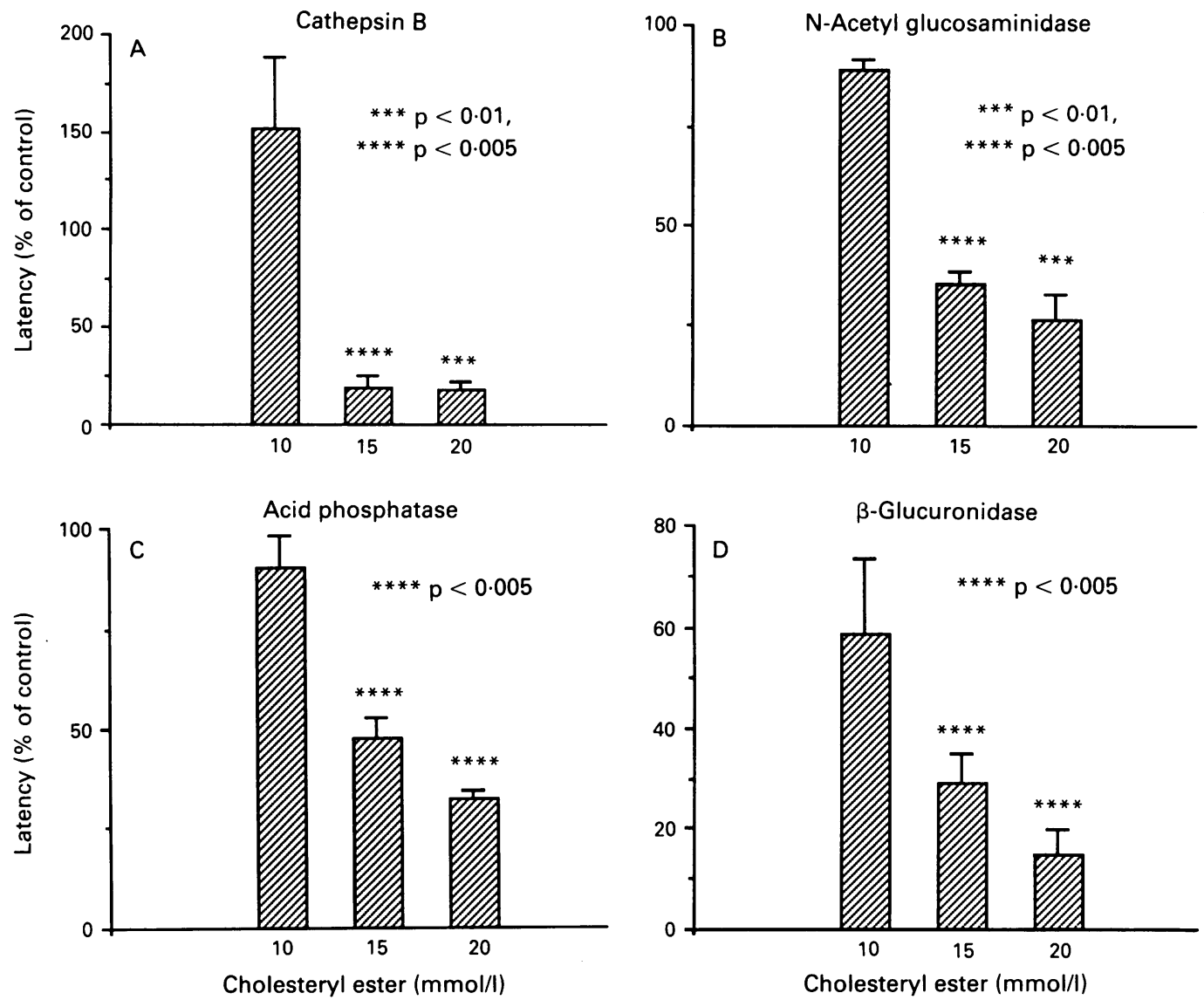

Figure 2 (a-d): Effect of cholesteryl ester on pancreatic lysosomal latency as an index of lysosomal stability (Methods). Results are expressed as per cent of control values and are presented as means (SEM) (four experiments). Control preparations contained phosphatidylcholine vesicles without cholesteryl ester.
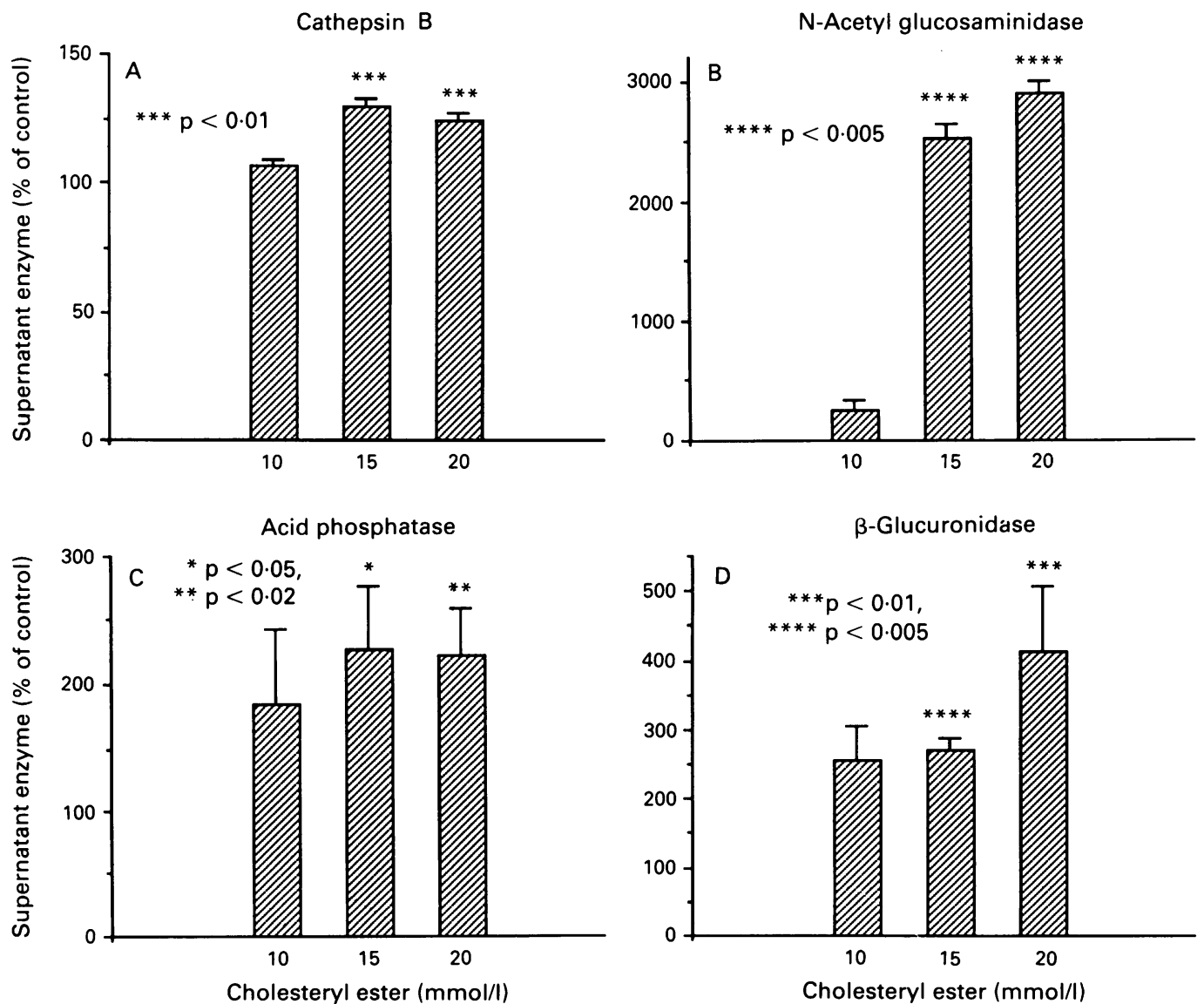

Figure $3(a-d)$ : Effect of cholesteryl ester on proportion of pancreatic lysosomal enzyme released into the supernatant as an index of lysosomal stability (Methods). Results are expressed as per cent of control values and are presented as means (SEM) (four experiments). Control preparations contained phosphatidylcholine vesicles without cholesteryl ester. 
latency. With all lysosomal enzymes studied, there was a progressive decrease in latency with increasing concentrations of cholesteryl oleate when compared with phosphatidylcholine controls. This decrease in latency was statistically significant with cholesteryl oleate concentrations of 15 and $20 \mathrm{mM}$.

Per cent of lysosomal enzymes in supernatant

Figure $3(\mathrm{a}-\mathrm{d})$ indicates the percentages of lysosomal enzymes released into the supernatant after incubation of isolated pancreatic lysosomes with phosphatidylcholine vesicles (with and without cholesteryl oleate) and subsequent resedimentation of lysosomes. Paralleling the findings observed with lysosomal latency (Fig 2), cholesteryl oleate (15 and $20 \mathrm{mM}$ ) resulted in significant increase in per cent of supernatant enzyme.

\section{EFFECT OF FREE FATTY ACID ON LYSOSOMAL STABILITY}

Free oleic acid $(50 \mu \mathrm{M})$ did not alter rat pancreatic lysosomal stability in vitro. Using acid phosphatase as a lysosomal marker enzyme, values for latency and supernatant enzyme (calculated as a per cent of control values and expressed as means (SEM)) were as follows: latency - $143.6(38 \cdot 7) \%$; supernatant enzyme $96 \cdot 4(2 \cdot 8) \%$ (four experiments).

\section{Discussion}

Experimental ethanol administration results in increased fragility of pancreatic lysosomes ${ }^{6}$ and the simultaneous accumulation of cholesteryl esters in the pancreas. ${ }^{1718}$ Ethanol induced fragility of pancreatic lysosomes has been observed in the absence of any morphologic evidence of pancreatic damage making it unlikely that it is a secondary phenomenon. ${ }^{17} 18$ This study shows that cholesteryl oleate can disrupt pancreatic lysosomes in vitro suggesting that cholesteryl esters may be responsible for the lysosomal fragility observed in vivo. In contrast, ethanol and acetaldehyde did not have any apparent deleterious effect on lysosomal stability.

The concentrations of cholesteryl ester seen to increase lysosomal fragility in vitro (15 and $20 \mathrm{mM}$ ) were greater than those observed in the rat pancreas in vivo $(5 \mathrm{mM}) .{ }^{18}$ The requirement for higher concentrations to disrupt pancreatic lysosomes may reflect the fact that, in an in vitro system, the period of incubation of isolated lysosomes with cholesteryl ester is necessarily limited ( 30 minutes in our study) whereas in the previous in vivo study, ${ }^{6}$ lysosomes were exposed to increased levels of cholesteryl esters for a much longer period (up to four weeks).

The effect of cholesteryl ester on pancreatic lysosomal latency appeared more pronounced than the effect on supernatant enzyme (Figs 2, 3) although significant changes in the proportion of supernatant enzyme were also seen. A somewhat similar result was observed in vivo where chronic ethanol administration was associated with decreased lysosomal latency but unaltered values for proportion of supernatant enzyme. ${ }^{6}$ This differential effect on the two parameters of lysosomal stability may indicate that the predominant effect of chronic ethanol administration and of cholesteryl ester is to increase the permeability of pancreatic lysosomal membranes rather than to completely disrupt the organelles. Thus, enzyme substrates may have greater access to enzymes within the lysosomes resulting in increased pre Triton enzyme activities and decreased latency (Methods). Complete disruption of lysosomes also occurs, but to a lesser extent resulting in less marked release of enzyme into the supernatant.

It is unlikely that the effect of cholesteryl esters on pancreatic lysosomes is an artefact related to release of free fatty acids during preparation or incubation of phosphatidylcholine vesicles. The maximum concentration of free fatty acids to which the lysosomes were exposed $(50 \mu \mathrm{M})$ did not disrupt pancreatic lysosomes after in vitro incubation.

The mechanism whereby cholesteryl esters decrease the stability of pancreatic lysosomes is not known. There have been only limited studies which directly address the effect of cholesteryl esters on the stability of biologic membranes. Forrest and Cushley $^{19}$ have reported that incorporation of cholesteryl esters increases the permeability of model membranes to ions 10 fold. Chronic ethanol administration to rodents has been shown to increase the cholesteryl ester content ${ }^{9}$ and to decrease the microviscosity of hepatic plasma membranes. ' In addition, there is evidence from the work of Hamilton and Small ${ }^{3+}$ that cholesteryl oleate molecules incorporated into model membranes are aligned with the carbonyl group close to the aqueous interface and the sterol ring and fatty acyl chain parallel to the acyl chains of phospholipid, thereby exerting a disordering effect.

It is conceivable that the observed destabilising effect of cholesteryl esters on lysosomes could be an indirect one, possibly mediated by disruption of zymogen granules in the lysosome enriched fraction and release of their contents. This is an unlikely explanation, however, for two reasons. First, pancreatic zymogen granules contain inactive precursors of the digestive enzymes (proteases, phospholipases) likely to be injurious to lysosomal membranes. Second, a protease inhibitor was used to counter any autoactivation which may have occurred during isolation.

The concentration of ethanol used $(150 \mathrm{mM})$ was much higher than that usually found in the blood of ethanol fed animals or alcoholic individuals. Despite such a relatively high concentration there was no demonstrable alteration in pancreatic lysosomal stability. Similarly, the acetaldehyde concentration used ( $5 \mathrm{mM}$ ), although much higher than that detected in vivo $(0-25 \mu \mathrm{M}),{ }^{35}{ }^{36}$ failed to produce any evidence of lysosomal damage. The lack of an acute effect of ethanol or acetaldehyde on pancreatic lysosomes in vitro, however, does not exclude the potential pancreatotoxicity of these compounds in vivo. For example, acetaldehyde has been shown to form circulating cytotoxic adducts with serum albumin. ${ }^{37}$ Furthermore, chronic ethanol consumption has recently been shown to increase 
the synthesis of pancreatic digestive enzymes ${ }^{38}$ and ethanol ${ }^{+0+1}$ and acetaldehyde ${ }^{+2}$ have been shown to inhibit pancreatic exocrine secretion. These latter changes could contribute to the increased glandular content of digestive enzymes observed after ethanol feeding ${ }^{18+3}$ and may predispose the gland to autodigestion.

The pathogenesis of alcoholic pancreatitis can be approached in two ways: (i) by studying factors influencing the individual susceptibility to the disease or (ii) by studying constant effects of ethanol on the pancreas. It is well known that only a minority of alcoholics are afflicted with clinical pancreatitis and the issue of individual susceptibility to alcoholic pancreatitis has recently been reviewed. ${ }^{++}$In essence, however, the predisposing factors remain unknown. ${ }^{+4}$ The study reported in this paper has adopted the latter approach and has explored one of the constant metabolic effects of ethanol on the pancreas - namely, increased lysosomal fragility, which may render the organ susceptible to autodigestion by facilitating contact between pancreatic digestive enzymes and lysosomal hydrolases.

This study has shown that cholesteryl esters can disrupt pancreatic lysosomes in vitro and thus supports the notion that cholesteryl esters may mediate the increased pancreatic lysosoma fragility observed after experimental ethano administration. Ethanol induced lysosomal fragility may permit release of lysosomal proteases and their subsequent contact with digestive enzymes, thereby predisposing the pancreas to autodigestion. The implication is that cholesteryl esters may play an important role in the pathogenesis of alcohol induced pancreatic injury.

This study was supported by the National Health and Medical Research Council of Australia. The authors are indebted to the Biomedical Mass Spectrometry Unit of the University of New South Wales.

1 Simsek H, Singh M. Ethanol and the pancreas. Current status. Gastroenterology 1990; 98: 1051-62.

2 Greenbaum LM, Hirschkowitz A. Endogenous cathepsi activates trypsinogen in extracts of dog pancreas. Proc Soc Exp Biol Med 1961; 107: 74-6.

3 Koike H, Steer ML, Meldolesi J. Pancreatic effects of ethionine: blockade of exocytosis and appearance of crin phagy and autophagy precede cellular necrosis. Am $\mathcal{F}$ Physio 1982; 242: G297-307

4 Watanabe O, Baccino FM, Steer ML, Meldolesi J. Supramaximal caerulein stimulation and ultrastructure of rat pancreatic acinar cell: early morphological changes during development of experimental pancreatitis. Am $\mathcal{f}$ Physiol 1984; 246: G457-67.

5 Saluja A, Saluja M, Villa A, Leli U, Rutledge P, Meldolesi J, et al. Pancreatic duct obstruction in rabbits causes digestive zymogen and lysosomal enzyme colocalization. $\mathcal{F}$ Clin Invest 1989; 84: $1260-6$.

6 Wilson JS, Korsten MA, Apte MV, Thomas MC, Haber PS, Pirola RC. Both ethanol and protein deficiency increase the fragility of rat pancreatic lysosomes. $\mathcal{F}$ Lab Clin Med 1990 115: 749-55.

7 Yamada S, Lieber CS. Decrease in microviscosity and cholesterol content of rat liver plasma membranes after chronic ethanol feeding. 7 Clin Invest 1984; 74: 2285-9.

8 Yamada S, Mak KM, Lieber CS. Chronic ethanol consump tion alters rat liver plasma membranes and potentiates release of alkaline phosphatase. Gastroenterology 1985; 88: $1799-806$

9 Zysset T, Polokoff MA, Simon FR. Effect of chronic ethano administration on enzyme and lipid properties of liver plasma membranes in long and short sleep mice. Hepatology 1985; 5: 531-7.

10 Kelly-Murphy S, Waring AJ, Rottenberg H, Rubin E. Effects of chronic ethanol consumption on the partition of lipophilic compounds into erythrocytic membranes. Lab Invest 1983 50: $174-83$.

11 Tillotson LG, Carter EA, Inui K, Isselbacher KJ. Inhibition of $\mathrm{Na}^{+}$-stimulated glucose transport function and perturbation of intestinal microvillus membrane vesicles by ethanol and acetaldehyde. Arch Biochem Biophys 1981; 207: 360-70.

12 Kalant H, Woo N, Endrenyi L. Effect of ethanol on the kinetics of rat brain $\left(\mathrm{Na}^{+}+\mathrm{K}^{+}\right)$ATPase and $\mathrm{K}^{+}$-dependent phosphatase with different alkali ions. Biochem Pharmacol 1978; $27: 1353-8$.

13 Barry RE, McGivan JD, Hayes M. Acetaldehyde binds to live cell membranes without affecting membrane function. $G u t$ 1984; 5: 412-6

14 Barry RE, McGivan JD. Acetaldehyde alone may initiate hepatocellular damage in acute alcoholic liver disease. $G u t$ 1985; 26: 1065-9.

15 Bordalo O, Goncalves D, Noronha M, Cristina ML, Salgadhino A, Dreiling DA. Newer concept for the pathogenesis of chronic alcoholic pancreatitis. Am $\mathcal{F}$ Gastroentero 1977; 68: 278-85.

16 Noronha M, Salgadhino A, Ferreira de Almeida MJ, Dreiling $\mathrm{DA}$, Bordalo $\mathrm{O}$. Alcohol and the pancreas, I Clinical associations and histopathology of minimal pancreatic inflammation. Am $\mathcal{f}$ Gastroenterol 1981; 76: 114-9.

17 Wilson JS, Colley PW, Sosula L, Pirola RC, Chapman BA Somer JB. Alcohol causes a fatty pancreas. A rat model of ethanol-induced pancreatic steatosis. Alcoholism: Clin Exp Res 1982; 6: 117-21.

18 Wilson JS, Korsten MA, Leo MA, Lieber CS. Combined effects of protein deficiency and chronic ethanol consumption on rat pancreas. Dig Dis Sci 1988; 33: 1250-9.

19 Forrest BJ, Cushley RJ. Cholesterol esters and membrane permeability: a nuclear magnetic resonance study. Atherosclerosis 1977; 28: 309-18.

20 Dawdowicz E. The effect of ethanol on membranes. Hepatology 1985; 5: 697-9.

21 Ignarro LJ, Oronsky AL, Perpe RJ. Effect of prostaglandins on release of enzymes from lysosomes of pancreas, spleen and kidney cortex. Life Sci 1973; 12: 193-201.

22 Chobanian JV, Tall AR, Brecher PI. Interaction between unilamellar egg yolk lecithin vesicles and human high density lipoprotein. Biochemistry 1979; 18: 180-7.

23 Barrow DA, Lentz BR. Large vesicle contamination in smal unilamellar vesicles. Biochim Biophys Acta 1980; 597: 92-9.

24 Barenholz Y, Gibbes D, Litman BJ, Goll J, Thompson TE Carlson FD. A simple method for the preparation of homogeneous phospholipid vesicles. Biochemistry 1977; 16 : 2806-10.

25 Tall AR, Deckelbaum RJ, Small DM, Shipley GG. Therma behaviour of human plasma high density lipoprotein. Biochim Biophys Acta 1977; 487: 145-53.

26 Huang C-H. Studies on phosphatidylcholine vesicles Formation and physical characteristics. Biochemistry 1969; 8: 344-9.

27 Howard-Black T. Methylation of free fatty acids using etheria diazomethane. Aldrichimica Acta 1983; 16: 3-10.

28 Nagai H, Henrich H, Wunsch P-H, Fischbach W, Mossner J. Role of pancreatic enzymes and their substrates in autodigestion of the pancreas. In vitro studies with isolated rat pancreatic acini. Gastroenterology 1989; 96: 838-47.

29 Mead JAR, Smith JN, Williams RT. The biosynthesis of the glucuronides of umbelliferone and 4-methylumbelliferone and their use in fluorimetric determination of $\beta$ glucuronidase. Biochem $\mathcal{F} 1955 ; 61$ : 569-74.

$30 \mathrm{McD}$ onald JK, Ellis S. On the substrate specificity of cathepsins $\mathrm{B} 1$ and $\mathrm{B} 2$ including a new fluorogenic substrate for cathepsin B1. Life Sci 1975; 17: 1269-76.

31 Saluja AK, Hashimoto S, Saluja M, Powers RE, Meldolesi J, Steer ML. Subcellular redistribution of lysosomal enzymes during cerulein-induced pancreatitis. Am $\mathcal{F}$ Physiol 1987 251: G508-16.

32 Lowry OH, Rosebrough NJ, Farr L, Randall RJ. Protein measurement with the Folin phenol reagent. 7 Biol Chem 1951; 193: 265-75.

33 Snedecor GW, Cochran WG, eds. Statistical methods. 8th ed. Ames, Iowa: Iowa State University Press, 1989: 38-64.

34 Hamilton JA, Small DM. Solubilization and localization of cholesteryl oleate in egg phosphatidylcholine vesicles. $\mathcal{F}$ Bio Chem 1982; 257: 7318-21.

35 Eriksson CJP. Human blood acetaldehyde concentration during ethanol oxidation (Update 1982). Pharmacol Biochem Behav 1983; 18: 141-50.

36 Eriksson CJP, Sippel HW. The distribution and metabolism of acetaldehyde in rats during ethanol oxidation - 1. Biochem Pharmacol 1977; 26: 241-7.

37 Wickramsinghe SN, Gardner B, Barden G. Cytotoxic protein molecules generated as a consequence of ethanol metabolism in vitro and in vivo. Lancet 1986; ii: 823-5.

38 Ponnappa BC, Hoek JB, Jubinski L, Rubin E. Effect of chronic ethanol ingestion on pancreatic protein synthesis. Biochem Biophys Acta 1988; 966: 390-402.

39 Korsten MA, Wilson JS, Lieber CS. Interactive effects of dietary protein and ethanol on rat pancreas. Gastroenterolog 1990; 99: 229-36.

40 Lewin MB, Sankaran H, Deveney CW, Wong A, Wendland MF, Geokas MC. Effect of ethanol on cholecystokinininduced enzyme secretion from isolated rat pancreatic acini. Biochem Pharmacol 1984; 33: 3225-9.

41 Hajnal F, Flores MC, Radley S, Valenzuela JE. Effect of alcohol and alcoholic beverages on meal-stimulated pancreatic

42 Sankaran H, Lewin MB, Wong A, Deveney CW. Irreversible inhibition by acetaldehyde of cholecystokinin-induced amylase secretion from isolated rat pancreatic acini. Biochem amylase secretion from isolated

43 Singh $M$, LaSure MM, Bockman DE. Pancreatic acinar cell function and morphology in rats chronically fed an ethanol diet. Gastroenterology 1982; 82: 425-34.

44 Wilson JS, Korsten MA, Pirola RC. Alcohol-induced pan creatic injury. Unexplained features and ductular theories of pathogenesis. Int $\mathcal{F}$ Pancreatol 1989; 4: 109-25. 